\title{
Investigation of the charges separation and transfer behavior of $\mathrm{BiOCl} / \mathrm{BiF}_{3}$ heterojunction
}

Yang Yang, Fei Teng, "Y Yandong Kan, Liming Yang, Zailun Liu, Wenhao Gu, An Zhang, Weiyi Hao, Yiran Teng

Jiangsu Engineering and Technology Research Center of Environmental Cleaning Materials (ECM), Jiangsu Collaborative Innovation Center of Atmospheric Environment and Equipment Technology (CICAEET), Jiangsu Key Laboratory of Atmospheric Environment Monitoring and Pollution Control (AEMPC), Jiangsu Joint Laboratory of Atmospheric Pollution Control (APC), School of Environmental Science and Engineering, Nanjing University of Information Science \& Technology, 219 Ningliu Road, Nanjing 210044, China

* Corresponding author. Tel./Fax.: +86-25-58731090; Email address: tfwd@163.com 


\begin{abstract}
To date, it is still a big challenge to investigate the charge transfer behavior from bulk to surface for the solar energy conversion and utilization. Herein, the $\mathrm{BiF}_{3} / \mathrm{BiOCl}$ heterojunction has been prepared through a mild post-synthesis method. Surface photovoltage spectra (SPV) results show that only negative SPV signal can be observed for $\mathrm{BiOCl}$, suggesting that the photogenerated electrons mainly move to the surfaces and accumulate on the surface; both negative and positive signals can be observed for $38 \% \mathrm{BiF}_{3} / \mathrm{BiOCl}$, indicating that photogenerated electrons and holes can both move to the surfaces and accumulate on the surface; but nearly no SPV signal can be observed for $\mathrm{BiF}_{3}$, demonstrating that nearly no electrons or holes can accumulate on the surface. Furthermore, under ultraviolet light irradiation $(\lambda \leq 420$ $\mathrm{nm})$, the degradation rate is 5.3 and 5.8 times higher than that of $\mathrm{BiOCl}$ and $\mathrm{BiF}_{3}$ for the degradation of 2-nitrophenol, respectively. We hold that the charges transfer and separation efficiency of $\mathrm{BiF}_{3} / \mathrm{BiOCl}$ have been significantly improved by the synergetic effect of the surface electric field, bulk internal electric field and interface electric field. This work could help us to intensively understand the charge transfer behavior of a heterojunction photocatalyst.
\end{abstract}

Keywords: charge transfer; surface electric field; bulk internal electric field; interface electric field 


\section{Introduction}

The conversion and utilization of solar energy, e.g., photocatalysis, has caused great attention because of its potential application in energy conversion, purifying wastewater and noxious gas [1-5]. To date, it is still a big challenge to investigate the charge transfer behavior from bulk to surface for the solar energy conversion and utilization. Many semiconductors have been developed, such as $\mathrm{TiO}_{2}$ [1], $\mathrm{ZnO}$ [6.7], $\mathrm{Ag}_{3} \mathrm{PO}_{4}[8-10], \mathrm{CdS}$ [11] and so on. However, the low charge separation efficiency limits the application in practices. Currently, bismuth-based semiconductors, including $\mathrm{BiVO}_{4}[12,13], \mathrm{BiWO}_{4}[14], \mathrm{Bi}_{3} \mathrm{PO}_{4}[15], \mathrm{Bi}_{2} \mathrm{O}_{2} \mathrm{CO}_{3}[16,17], \mathrm{BiOX}(\mathrm{X}=\mathrm{Cl}$, $\mathrm{Br}, \mathrm{I})$ [18-21], etc. have shown efficient photocatalytic activities in wastewater and noxious gas purification. Among them, layer structured $\mathrm{BiOCl}$ (composed of $\left[\mathrm{Bi}_{2} \mathrm{O}_{2}\right]^{2+}$ layers interleaved with $\mathrm{Cl}$ layers) have attracted great interests due to its outstanding optical and electrical properties [22,23]. However, its photocatalytic activity is obviously limited by the wide band gap and high recombination rate of photogenerated carries [24,25]. Moreover, it is still a big challenge to investigate the charge transfer behavior of photocatalysts. Up to now, many efforts have been made to enhance the photocatalytic performance of $\mathrm{BiOCl}$, such as metal doping $(\mathrm{Fe}, \mathrm{Zn}$, $\mathrm{Cu}, \mathrm{Mn}$, etc.) [23,26-28], nonmetal doping (F, C, etc.) [19,29], co-catalyst modification (Ag, $\mathrm{Au}, \mathrm{Bi}$ etc.) [30-35] and semiconductor heterojunctions ( $\mathrm{BiOI} / \mathrm{BiOCl}[36], \mathrm{Bi}_{2} \mathrm{~S}_{3} / \mathrm{BiOCl}$ [37], $\mathrm{Ag} / \mathrm{AgX} / \mathrm{BiOX}[21,38], \mathrm{BiOCl} / \mathrm{Ag}_{3} \mathrm{PO}_{4}$ [39], $g-\mathrm{C}_{3} \mathrm{~N}_{4} / \mathrm{BiOCl}[25,40], \mathrm{Bi}_{2} \mathrm{O}_{2} \mathrm{CO}_{3} / \mathrm{BiOCl}$ [41], $\mathrm{TiO}_{2-\mathrm{x}} / \mathrm{BiOCl}$ [42], etc.). Among the various strategies, heterojunction is one of the most efficient strategies for the enhancement of photocatalytic activity [43] because the low charge transfer and separation is one of the most impediments for photocatalysis. Recently, $\mathrm{BiF}_{3}$ have 
been reported as a new, efficient photocatalyst in our group [44], which has a highly positive valence band $(6.04 \mathrm{eV})$ and an excellent electrical conductivity. Moreover, $\mathrm{BiF}_{3}$ has the matched energy bands with $\mathrm{BiOCl}[45]$. We expect that compared with $\mathrm{BiF}_{3}$ and $\mathrm{BiOCl}, \mathrm{BiF}_{3} / \mathrm{BiOCl}$ heterojunction may have an improved activity, which has not been reported yet.

Herein, a mild post-synthesis method has been developed to prepare $\mathrm{BiF}_{3} / \mathrm{BiOCl}$ heterojunction by using $\mathrm{BiOCl}$ and $\mathrm{NH}_{4} \mathrm{~F}$ as the precursors. A plausible conversion mechanism has been proposed. The physical properties of as-obtained samples are characterized by X-ray diffraction (XRD), scanning electron microscopy (SEM), high-resolution transmission electron microscopy (HRTEM), selected area electron diffraction (SAED), UV-visible diffuse reflectance spectroscopy (UV-DRS) and $\mathrm{N}_{2}$ sorption isotherms. Additionally, the charge behaviors of samples are measured by electrochemical impedance spectroscopy (EIS), and photoluminescence (PL) spectra. The surface charge behavior is mainly revealed by the surface photovoltage spectra (SPV) [46,47]. In addition, the photocatalytic performances of the samples were tested by the degradation of methyl orange (MO) and 2-nitrophenol aqueous solutions $[42,48]$. The capturing experiments were also performed to investigate the main active oxidative species $[40,49]$. We expect that this work could help us to intensively understand the charge transfer behavior of photocatalysts. 


\section{Experimental}

\subsection{Sample preparation}

All reagents were of analytical grade, purchased from Beijing Chemical Reagents Industrial Company of China, and were used without further purification.

Preparation of $\mathrm{BiOCl}$. $\mathrm{BiOCl}$ sample was prepared according to our previously reported method [45]. Typically, $1.5 \mathrm{mmol}$ of $\mathrm{Bi}\left(\mathrm{NO}_{3}\right)_{3} \cdot 5 \mathrm{H}_{2} \mathrm{O}$ was dissolved in $30 \mathrm{~mL}$ of ethylene glycol (EG) under stirring at room temperature. After the $\mathrm{Bi}\left(\mathrm{NO}_{3}\right)_{3} \cdot 5 \mathrm{H}_{2} \mathrm{O}$ was completely dissolved, $10 \mathrm{mmol}$ of $\mathrm{NaCl}$ was added to the above solution. After being stirring for $30 \mathrm{~min}$, the solution was transferred into a 50-mL Teflon-lined stainless steel autoclave, and then maintained at $170{ }^{\circ} \mathrm{C}$ for $6 \mathrm{~h}$. After reaction, the autoclave was cooled to room temperature naturally. The resulting sample was centrifuged and washed with ethanol and distilled water three times, and then dried at $60{ }^{\circ} \mathrm{C}$ for $3 \mathrm{~h}$. The obtained sample was designated as BF-0.

Preparation of $\mathrm{BiF}_{3} / \mathrm{BiOCl}$ and $\mathrm{BiF}_{3}$. Typically, $1 \mathrm{mmol}$ as-obtained $\mathrm{BiOCl}$ (0.2605 g) above was dispersed into a $20 \mathrm{~mL}$ of ethanol, then, 1, 2, 4 and $6 \mathrm{mmol}$ $\mathrm{NH}_{4} \mathrm{~F}$ was added into the solution above, respectively. After being stirring for $30 \mathrm{~min}$, the mixture solutions was transferred to Teflon-lined stainless steel autoclave, and maintained at $170{ }^{\circ} \mathrm{C}$ for $6 \mathrm{~h}$. The resulting precipitate was centrifuged, washed with ethanol and distilled water for three times and dried at $60{ }^{\circ} \mathrm{C}$ for $3 \mathrm{~h}$. The as-obtained samples at 1, 2, 4 and 6 mmol of $\mathrm{NH}_{4} \mathrm{~F}$ were designated as BF-1, BF-2, BF-3 and $\mathrm{BF}-4$, respectively.

\subsection{Characterization}

The crystal structures of the samples were determined by X-ray powder 
polycrystalline diffractometer (XRD, Rigaku D/max-2550VB), using graphite monochromatized $\mathrm{Cu} \mathrm{K} \mathrm{K}_{\alpha}$ radiation $(\lambda=0.154 \mathrm{~nm})$, operating at $40 \mathrm{kV}$ and $50 \mathrm{~mA}$. The XRD patterns were obtained in the range of $10-80^{\circ}(2 \theta)$ at a scanning rate of $7^{\circ}$ $\min ^{-1}$. The samples were characterized by a scanning electron microscope (SEM, Hitachi SU-1510) with an acceleration voltage of $15 \mathrm{keV}$. The samples were coated with 5-nm-thick gold layer before observations. The fine surface structures of the samples were determined by high-resolution transmission electron microscopy (HRTEM, JEOL JEM-2100F) equipped with an electron diffraction (ED) attachment with an acceleration voltage of $200 \mathrm{kV}$. Nitrogen sorption isotherms were performed at $77 \mathrm{~K}$ and $<10^{-4}$ bar on a Micromeritics ASAP2010 gas adsorption analyzer. Each sample was degassed at $150{ }^{\circ} \mathrm{C}$ for $5 \mathrm{~h}$ before measurements. Surface area was calculated by the Brunauer-Emmett-Teller (BET) method. UV-diffused reflectance spectra of the samples were obtained using a UV-spectrophotometer (UV-2550, Shimadzu, Japan). $\mathrm{BaSO}_{4}$ was used as a reflectance standard in a UV-vis diffuse reflectance experiment. All the electrochemical measurements were carried out on a CHI 660D electrochemical working stations at room temperature. For a standard three-electrode cell, a $0.2 \mathrm{M} \mathrm{Na}_{2} \mathrm{SO}_{4}$ aqueous solution was used as the electrolyte. ITO (with an area of $2 \mathrm{~cm}^{2}$ ) was used as the current collector of working electrode for detecting photocurrent response and Ni film (with an area of $1 \mathrm{~cm}^{2}$ ) was used as the current collector of working electrode for testing EIS. Pt wire (diameter: $0.1 \mathrm{~cm}$, length: $4 \mathrm{~cm}$ ) and $\mathrm{Hg} / \mathrm{HgO}($ S.C.E) electrodes were used as the counter and reference electrodes. To fabricate the working electrode, $80 \mathrm{wt} \%$ of active materials, $10 \mathrm{wt} \%$ of acetylene black (conductive agent) and $10 \mathrm{wt} \%$ of vinylidene fluoride (binder) were dispersed in 1-methyl-2-pyrrolidinone to form homogeneous slurry. Then the slurry was dotted on the ITO or $\mathrm{Ni}$ film and dried for $24 \mathrm{~h}$ at room temperature. 
Electrochemical impedance spectroscopy (EIS) was performed from $0.01 \mathrm{~Hz}$ to 100 $\mathrm{kHz}$ at an open circuit potential of $0.3 \mathrm{~V}$ and alternating current (AC) voltage amplitude of $5 \mathrm{mV}$. The photo electrodes were prepared by a dip-coating method and $0.2 \mathrm{M} \mathrm{Na}_{2} \mathrm{SO}_{4}$ was used as the electrolyte solution. The data were analyzed by ZSimWin software. The photoluminescence (PL) spectra were obtained on Cary Eclipse fluorescence spectrophotometer at room temperature under the $265 \mathrm{~nm}$ laser excitation (Cary Eclipse, Agilent).

\subsection{Surface photovoltage (SPV) measurement}

Surface photovoltage (SPV) measurement system [46,47] is consist of a monochromatic light source, a lock-in amplifier (SR830-DSP) with a light chopper (SR540), a photovoltaic cell and a computer. The monochromatic light is provided by

a 500 W xenon lamp (CHFXQ500 W, Global Xenon Lamp Power) and a double-prism monochromator (Zolix SBP500). During the SPV measurement, the samples were test without further treatment. While the measurement of surface photovoltage was performed, the contact between the samples and the indium tin oxide (ITO) electrode was not ohmic. The construction of the photovoltaic cell is a sandwich like structure, which consist of steel timber, sample and ITO. We placed the powders on the steel timber electrode, then, the powder was pressed to obtain a film with ITO electrode.

\subsection{Evaluation of photocatalytic activity}

The photodegradation reactions of methyl orange (MO) and 2-nitrophenol were carried out to evaluate the catalytic activities under ultraviolet light irradiation $(\lambda \leq$ $420 \mathrm{~nm}$ ), using a $500 \mathrm{~W}$ Xe arc lamp (CEL-HXF 300) equipped with a cutoff filter 
$(\lambda>420 \mathrm{~nm})$ as a light source. Typically, $0.1 \mathrm{~g}$ of powders was suspended in $200 \mathrm{~mL}$ aqueous solution of $\mathrm{MO}\left(12.5 \mathrm{mg} \mathrm{L}^{-1}\right)$ or 2-nitrophenol (4.5 $\left.\mathrm{mg} \mathrm{L}^{-1}\right)$ under continuous magnetic stirring. Before light-on, the suspension was stirred for $30 \mathrm{~min}$ to reach an adsorption-desorption equilibrium of organic molecules on the photocatalyst surface. During reaction, $3 \mathrm{~mL}$ of suspension was collected at a given interval time and centrifuged to remove the powders. The concentration of pollutant was determined by using UV-vis spectrophotometer. Herein, the degradation efficiency of MO and 2-Nitrophenol can be simplified as a pseudo-first-order kinetic reaction, and the apparent reaction rate constants $\left(k_{a}\right)$ are calculated by the formula (4) as follows $[42,48]$.

$$
\ln \left(C_{0} / C\right)=k_{a} t
$$

where $\mathrm{C}$ is the concentration of $\mathrm{MO}$ and 2-nitrophenol remaining in solution at different irradiation time, and $\mathrm{C}_{0}$ is the initial concentration before irradiation.

In order to investigate the active species, ammonium oxalate, isopropyl alcohol (IPA) and benzoquinone (BQ) were employed as the scavengers to capture holes $\left(\mathrm{h}^{+}\right)$, hydroxyl radicals $(\bullet \mathrm{OH})$ and superoxide radical $\left(\bullet \mathrm{O}_{2}{ }^{-}\right)$, respectively $[40,49,50]$. The other procedures were same as above. 


\section{Results and Discussion}

\subsection{Effect of Bi/F molar ratio on the samples}

Figure 1a shows the XRD patterns of the samples. All the diffraction peaks of the as-prepared BF-0 sample are in good agreement with the standard BiOCl (JCPDS No. 06-0249), indicating the formation of phase-pure BiOCl. At $\mathrm{Bi}: \mathrm{F}=1: 1,1: 2$ and 1: 4, $\mathrm{BiF}_{3}$ (No. 73-1988) form besides $\mathrm{BiOCl}$, indicating that a part of $\mathrm{BiOCl}$ has converted into $\mathrm{BiF}_{3}$; Moreover, the peak intensities of $\mathrm{BiF}_{3}$ (at $2 \mathrm{Theta}=30.5^{\circ}, 43.6^{\circ}$ and $51.7^{\circ}$ ) increase with increasing the amount of $\mathrm{NH}_{4} \mathrm{~F}$ added. At $\mathrm{Bi}: \mathrm{F}=1: 6$, the XRD patterns of BF-4 sample are in accordance with the standard $\mathrm{BiF}_{3}$ (No. 73-1988), which indicates that the phase-pure $\mathrm{BiF}_{3}$ has formed. The SEM images of the samples are shown in Figure 1(b-f). The as-prepared $\mathrm{BiOCl}$ sample is composed of the microspheres assembled by the nanosheets with the diameters of $4 \sim 7 \mu \mathrm{m}$. After treated by $\mathrm{NH}_{4} \mathrm{~F}$, the microspheres have obviously broken into nanosheets, and some of irregular particles have formed (Figure $1(\mathrm{c}-\mathrm{f})$ ). When $\mathrm{NH}_{4} \mathrm{~F}$ is substituted by $\mathrm{NaF}$, however, the as-obtained sample is still the phase-pure $\mathrm{BiOCl}$ (Figure $\mathrm{S} 1 \mathrm{a}$, in supporting information (SI)). These results above indicate that $\mathrm{NH}_{4} \mathrm{~F}$ has a significant impact on the phase composition and morphology of the sample.

In ethanol, the reaction between $\mathrm{BiOCl}$ and $\mathrm{NH}_{4} \mathrm{~F}$ is like a solution-solution reaction, because both $\mathrm{BiOCl}$ and $\mathrm{NH}_{4} \mathrm{~F}$ could dissolve in ethanol. Herein, we assume that $\mathrm{NH}_{4}{ }^{+}$, as a Lewis acid, can destroy the $\left[\mathrm{Bi}_{2} \mathrm{O}_{2}\right]$ layers. At lower amount of $\mathrm{NH}_{4} \mathrm{~F}$ added $(\mathrm{Bi}: \mathrm{F}=1: 1,1: 2$ and $1: 4)$, the $\left[\mathrm{Bi}_{2} \mathrm{O}_{2}\right]$ slabs may have been partially destroyed, so tetragonal $\mathrm{BiOCl}$ has partially converted into cubic $\mathrm{BiF}_{3}$. As a result, $\mathrm{BiF}_{3} / \mathrm{BiOCl}$ heterojunctions have formed. Further increasing the amount of $\mathrm{NH}_{4} \mathrm{~F}$ (Bi:F=1:6) added, the $\left[\mathrm{Bi}_{2} \mathrm{O}_{2}\right]$ slabs may have been destroyed completely. As a result, tetragonal 
$\mathrm{BiOCl}$ has completely converted into cubic $\mathrm{BiF}_{3}$ treated by $\mathrm{NH}_{4} \mathrm{~F}$ in the medium of ethanol solution. However, $\mathrm{NaF}$ is insoluble in ethanol, so the reaction is via a solid-solution reaction. In addition, the $\left[\mathrm{Bi}_{2} \mathrm{O}_{2}\right]$ layers cannot be destroyed by $\mathrm{NaF}$, hence, $\mathrm{BiOCl}$ can not convert to $\mathrm{BiF}_{3}$ or $\mathrm{BiOF}$. When we substitute ethanol for distilled water as the reaction medium $\left(\mathrm{NH}_{4} \mathrm{~F}\right)$, nevertheless, $\mathrm{BiOCl}$ has converted into $\mathrm{BiOF}$, instead of $\mathrm{BiF}_{3}$ (Figure $\left.\mathrm{S} 1 \mathrm{~b}, \mathrm{SI}\right)$. We hold that when water is employed as the medium, a solid-solution reaction mainly occurs. In the presence of $\mathrm{NH}_{4}^{+}\left(\mathrm{NH}_{4}^{+}+\right.$ $\mathrm{H}_{2} \mathrm{O} \rightarrow \mathrm{NH}_{3} \cdot \mathrm{H}_{2} \mathrm{O}+\mathrm{H}^{+}$), BiOCl solids could dissolve partially. As a result, BiOCl, $\left[\mathrm{Bi}_{2} \mathrm{O}_{2}\right]^{2+}$ and $\mathrm{Cl}^{-}$may be present simultaneously in aqueous solution. Moreover, $\mathrm{F}^{-}$ will gradually replace $\mathrm{Cl}^{-}$to form BiOF crystal due to a strong electronegativity of $\mathrm{F}^{-}$. It should be noted that the real conversion mechanism still needs further investigation. However, this conversion process is mild and meaningful to obtain new materials.

Further, BF-1 sample is typically characterized by the high-resolution transmission electron microscopy (HRTEM) and selected-area electron diffraction (SAED) patterns (Figure 2). Figure 2a shows that the nanoparticles distribute on the nanosheets. As shown in Figure 2b, the lattice spacing of $0.28 \mathrm{~nm}$ is close to the (110) plane $(0.275 \mathrm{~nm})$ of $\mathrm{BiOCl}[45]$, and the lattice spaces of 0.21 and $0.34 \mathrm{~nm}$ well match the (220) $(0.207 \mathrm{~nm})$ and (111) $(0.338 \mathrm{~nm})$ planes of $\mathrm{BiF}_{3}$, respectively. Additionally, Figure 2c shows that the clear diffraction spots correspond to the (110) Bragg reflections of single-crystal $\mathrm{BiOCl}$, and the diffraction rings correspond to (111) and (220) Bragg reflections of polycrystalline $\mathrm{BiF}_{3}$, respectively. The results above firmly confirm the formation of $\mathrm{BiF}_{3} / \mathrm{BiOCl}$ heterojunction. 


\subsection{Optical and charge transfer properties of the samples}

We have investigated the optical and charge transfer properties of the samples by XPS, UV-DRS, EIS, Photocurrent, PL and SPV.

XPS Analysis. XPS analysis was employed to explore surface chemical state and composition of the samples. From the survey spectrum shown in Figure 3a, the peaks of $\mathrm{Bi}, \mathrm{O}$ and $\mathrm{Cl}$ can be found for $\mathrm{BF}-0, \mathrm{BF}-1, \mathrm{BF}-2$ and $\mathrm{BF}-3$ samples. However, the peaks of $\mathrm{F}$ can be found for BF-1, BF-2, BF-3 and BF-4 samples. In Figure 3b, two main peaks with the binding energies at about $158-160 \mathrm{eV}$ and $164-166 \mathrm{eV}$ are corresponding to the $\mathrm{Bi} 4 \mathrm{f}_{7 / 2}$ and $\mathrm{Bi} 4 \mathrm{f}_{5 / 2}$ of $\mathrm{Bi}^{3+}$, respectively [22]. It is noteworthy that the band energies of $\mathrm{Bi}^{3+}$ in $\mathrm{BF}-4\left(\mathrm{BiF}_{3}\right)$ are slightly higher than that of $\mathrm{BF}-0$ (BiOCl) sample. Hence, compared with BF-0, the blue shifts occur in BF-1, BF-2, BF-3 indicates the increased amounts of $\mathrm{BiF}_{3}$. In Figure 3c, the peaks at about 198.5 and $199.8 \mathrm{eV}$ could be ascribed to $\mathrm{Cl} 2 \mathrm{p}_{3 / 2}$ and $\mathrm{Cl} 2 \mathrm{p}_{1 / 2}$ for BF-0, BF-1, BF-2 and BF-3 samples, respectively [43]. Figure $3 d$ shows that the F 1 s spectrum could be observed at about $683.5 \mathrm{eV}$ for BF-1, BF-2, BF-3 and BF-4 samples. The above results also demonstrate that $\mathrm{BiOCl}$ could be converted to $\mathrm{BiF}_{3}$ eventually with increasing $\mathrm{NH}_{4} \mathrm{~F}$. Additionally, Table 1 summarizes the calculated mole percents of $\mathrm{Cl}$ and F. The XPS spectrums of O 1s are shown in Figure S2. According to the molar ratios of $\mathrm{F}$ and $\mathrm{Cl}$, we can obtain the approximate molar ratios of $\mathrm{BiF}_{3}$ to $\mathrm{BiOCl}$ of the samples, also given in Table 1. From the calculated results, the molar ratios of $\mathrm{BiF}_{3}$ to $\mathrm{BiOCl}$ are about $38 \%, 65 \%$ and $165 \%$ for $\mathrm{BF}-1, \mathrm{BF}-2$ and $\mathrm{BF}-3$ samples, respectively. Additionally, EDS is also employed to analyze the molar ratios of $\mathrm{BiF}_{3}$ and $\mathrm{BiOCl}$, which have been discussed in supporting information (section 1.1, SI). The results show that the elements contents are different from the XPS and EDS results (Table S1 and Figure S3) demonstrating the distribution of $\mathrm{BiF}_{3}$ and $\mathrm{BiOCl}$ are not uniform. 
$\boldsymbol{U V}$-DRS Analysis. Figure 4a displays the UV-visible diffuse reflectance spectra (UV-DRS) of the samples. All the samples exhibit the light absorption in UV light ranges. The absorption edges of $\mathrm{BF}-0(\mathrm{BiOCl}), \mathrm{BF}-1\left(38 \% \mathrm{BiF}_{3} / \mathrm{BiOCl}\right), \mathrm{BF}-2(65 \%$ $\left.\mathrm{BiF}_{3} / \mathrm{BiOCl}\right), \mathrm{BF}-3\left(165 \% \mathrm{BiF}_{3} / \mathrm{BiOCl}\right)$ and $\mathrm{BF}-4\left(\mathrm{BiF}_{3}\right)$ are determined to be about 353, 350, 348, 345 and $310 \mathrm{~nm}$, respectively. The band gaps of BF-0, BF-1, BF-2, BF-3 and BF-4 are 3.51, 3.54, 3.56, 3.59 and $4.02 \mathrm{eV}$, respectively. Compared with $\mathrm{BiOCl}$, all the treated samples show obvious blue-shifts and the increased band gaps. In addition, the band gap of semiconductors also can be calculated by Kubelka-Munk (KM) expression [51]:

$$
\alpha h v=A\left(h v-E_{g}\right)^{\mathrm{n} / 2}
$$

where $\alpha, h, v, A$ and $E_{g}$ are absorption coefficient, Planck's constant, photon frequency, proportionality constant and band gap, respectively. According to the plots of $(\alpha h v)^{2}$ vs. photo energy (Figure 4b), the band gaps of $\mathrm{BiOCl}$ and $\mathrm{BiF}_{3}$ are calculated to be 3.51 and $4.02 \mathrm{eV}$, respectively. It is worth noting that BF-1 and BF-2 samples show the enhanced absorption abilities than other samples in the wavelength range from about 350 to $800 \mathrm{~nm}$.

Further, the conduction and valence band positions $\left(E_{C B}, E_{V B}\right)$ of a semiconductor can be calculated by the following empirical formula [52]:

$$
\begin{aligned}
& E_{V B}=\chi-E^{e}+0.5 E_{g} \\
& E_{C B}=E_{V B}-E_{g}
\end{aligned}
$$

where $\chi$ is the absolute electronegativity of a semiconductor, which is defined as the geometric mean of the absolute electronegativity of constituent atoms; $E^{e}$ is the energy of free electrons on the hydrogen scale $(c a .4 .5 \mathrm{eV})$. The specific calculation processes are shown in supporting information (section 1.2, SI). Herein, the calculated $E_{C B}$ and $E_{V B}$ values of $\mathrm{BiOCl}$ and $\mathrm{BiF}_{3}$ samples are summarized in Table 2. It is 
obvious that the $\mathrm{CB}(0.4 \mathrm{eV})$ of $\mathrm{BiOCl}$ lies above that $(2.02 \mathrm{eV})$ of $\mathrm{BiF}_{3}$, while the $\mathrm{VB}$ $(6.04 \mathrm{eV})$ of $\mathrm{BiF}_{3}$ lies below that $(3.91 \mathrm{eV})$ of $\mathrm{BiOCl}$. This suggests that a stable heterojunction can form between $\mathrm{BiF}_{3}$ and $\mathrm{BiOCl}$.

EIS Analysis. Figure 5a shows the electrochemical impedance spectra (EIS) of the samples. It is well known that the smaller arc radius indicates a higher electrical conductivity, which will favors for an efficient electron transfer $[16,53,54]$. The simulated equivalent electric circuit from EIS Nyquist plots consists of a solution resistance $\left(\mathrm{R}_{\mathrm{s}}\right)$, a constant phase element (CPE) accounting for electrical double-layer capacitance, a charge-transfer resistance $\left(\mathrm{R}_{\mathrm{ct}}\right)$, and a Warburg impedance $(\mathrm{W})$ for the diffusion and insertion of ion into active materials. The $\mathrm{R}_{\mathrm{ct}}$ values of $\mathrm{BiOCl}, \mathrm{BF}-1$, BF-2, BF-3 and BF-4 $\left(\mathrm{BiF}_{3}\right)$ are calculated to be $2.83,1.85,2.54,2.32$ and $0.46 \Omega$, respectively. This clearly demonstrates the charge-transfer resistance $\left(\mathrm{R}_{\mathrm{ct}}\right)$ of $\mathrm{BiF}_{3}$ is obviously smaller than $\mathrm{BiOCl}$, and the charge-transfer ability of all $\mathrm{BiF}_{3} / \mathrm{BiOCl}$ heterojunctions are higher than $\mathrm{BiOCl}$, but lower than $\mathrm{BiF}_{3}$. We believe that the formed interfacial electric field between $\mathrm{BiOCl}$ and $\mathrm{BiF}_{3}$ is the crucial factor for the enhanced transfer and separation efficiency of photogenerated charges, which will improve its photocatalytic activity.

Photocurrent Analysis. Additionally, photocurrent response spectrum is an important method to investigate the interfacial charge separation and transfer efficiency $[16,55]$. Herein, the photocurrent response spectra of the samples are performed under UV-light irradiation $(\lambda \leq 420 \mathrm{~nm})$. As shown in Figure $5 \mathrm{~b}, \mathrm{BF}-4$ $\left(\mathrm{BiF}_{3}\right)$ sample shows a higher charge separation dynamics than BF-0 (BiOCl). Moreover, $\mathrm{BiF}_{3} / \mathrm{BiOCl}$ heterojunctions show much higher separation efficiencies than $\mathrm{BiOCl}$ and $\mathrm{BiF}_{3}$.

PL Analysis. As is known, the photoluminescence (PL) spectroscopy has been 
widely used to investigate the optical properties and the recombination rate of electrons and holes pairs [55]. Figure 5c shows PL spectra of the samples with the excitation wavelength of $265 \mathrm{~nm}$. The PLintensity of BF-1 sample is much lower than those of the other samples, indicating that the lower recombination efficiency of photogenerated carriers could favor for the improvement of photocatalytic activity.

SPV Analysis. Figure 5d shows the SPV spectra of the samples. BF-0 (BiOCl) exhibits a negative SPV signal in the range of 300 to $425 \mathrm{~nm}$, indicating that the photogenerated electrons move from the bulk to the surface of $\mathrm{BiOCl}$, and the photogenerated holes migrate from the surface to the bulk [46]. For BF-3 and BF-4 $\left(\mathrm{BiF}_{3}\right)$ samples, only much weak negative SPV signals can be observed, which means that only fairly fewer photogenerated electrons can move to the surfaces of the samples. This would result in poor photocatalytic performance. However, both intensive positive and negative signals are observed for BF-1 and BF-2 samples, indicating that both electrons and holes can move to the surfaces and accumulate under different wavelength light illuminating. The similar results have been observed in $\mathrm{BiVO}_{4}$ heterophase composites reported by Fan et al. [47] As shown in Figure S4, when the wavelength of incident light is in the range of 320-353 nm, only BiOCl can be excited, but $\mathrm{BiF}_{3}$ can not. In this case, the generated electrons of $\mathrm{BiOCl}$ cannot move to the $\mathrm{BiF}_{3}$, and the $\mathrm{BiF}_{3} / \mathrm{BiOCl}$ heterojunction only shows a negative SPV signal that mainly results from $\mathrm{BiOCl}$.

From the UV-DRS (Figure 4a), we can see that both the BF-1 and BF-2 samples still have a small light absorption at the wavelength of $353-500 \mathrm{~nm}$, which can attribute to the sub-gap transition [56].It is well known that the light absorbed by shallow energy level and surface state can result in the sub-gap transition [56,57]. Herein, the shallow energy levels of a semiconductor are the electronic bound states 
close to conductive band bottom and/or the hole bound states close to valence band top. Under light irradiation or heating, the electrons and/or holes are easy to ionize and escape from shallow energy levels, then become the free electrons in CB and/or the free holes in VB [57]. For a semiconductor, the surface states are ubiquitous due to dangling chemical bond on the solid surfaces caused by periodic crystal lattice interruption, or defects, or adsorbed impurities on the crystal surface. These surface states (surface energy levels) can also bound electrons or holes [58,59].

On one hand, while being irradiated by the incident light $(353-500 \mathrm{~nm})$, the electrons or holes in the shallow energy level of $\mathrm{BiF}_{3} / \mathrm{BiOCl}$ interfaces $(\mathrm{BF}-1$ and BF-2) would absorb the photons, then escape from the shallow energy level and become the free electrons in conduction band or free holes in valence band. With the separation of electrons and holes in the shallow energy levels, the SPV signal would be generated. On the other hand, the visible emission also occurred in $\mathrm{ZnO}$ with a band gap of $3.2 \mathrm{eV}$, which has been attributed to the surface defect states [57]. Hence, we hold that the surface state of material also contributes to the generation of SPV signal at the wavelengths of 353-500 nm.

Summarily, we hold that the SPV signals at the wavelength of 353-500 nm are resultant from the light absorption by shallow energy level and surface state. Under the UV light irradiation (300-320 nm), however, both $\mathrm{BiOCl}$ and $\mathrm{BiF}_{3}$ can be excited. Hence, the generated electrons on the $\mathrm{CB}$ of $\mathrm{BiOCl}$ would move to the $\mathrm{CB}$ of $\mathrm{BiF}_{3}$, and the generated holes on the $\mathrm{VB}$ of $\mathrm{BiF}_{3}$ would transfer to that of $\mathrm{BiOCl}$. As a result, the $\mathrm{BiF}_{3} / \mathrm{BiOCl}$ heterojunction is efficient, which benefits the charges transfer. When the holes move to surface of BiOCl, the positive SPV signal occurred. 


\subsection{Photocatalytic activities of the samples}

Figure $6(a, b)$ shows the degradation curves and reaction kinetic curves of methyl orange (MO) dye under UV light irradiation $(\lambda \leq 420 \mathrm{~nm})$. The degradation activities of the samples follow the order as follows: BF-1 $>$ BF-2 $>$ BF-0 $>$ BF-3 $>$ BF-4. After being irradiated for 30 min, nearly $90 \%$ and $77 \%$ of $\mathrm{MO}$ have been degraded by BF-1 and BF-2 samples, respectively; however, only 46\%, 43\% and $22 \%$ of $\mathrm{MO}$ have been degraded by $\mathrm{BF}-0(\mathrm{BiOCl}), \mathrm{BF}-3$ and $\mathrm{BF}-4\left(\mathrm{BiF}_{3}\right)$, respectively. The degradation rate constants $\left(k_{a}\right)$ are given in Table 3 . The degradation rate constant $\left(k_{a}=0.0607 \mathrm{~min}^{-1}\right)$ of BF-1 sample is 3.08 and 11.9 times higher than those of the untreated $\mathrm{BiOCl}\left(k_{a}=0.0197 \mathrm{~min}^{-1}\right)$ and $\mathrm{BiF}_{3}\left(k_{a}=0.0051 \mathrm{~min}^{-1}\right)$, respectively. It is obvious that the $38 \% \mathrm{BiF}_{3} / \mathrm{BiOCl}$ heterojunction $(\mathrm{BF}-1)$ shows the highest activity than the others for the degradation of MO. Additionally, the photocatalytic activities of the sample synthesized in $\mathrm{Bi}: \mathrm{F}=1: 0.5$ and commercial P25 were shown in Figure S5 and S6. From Figure S5b, we can see that the photocatalytic activity of BF-1 is better than that of the sample synthesized at $\mathrm{Bi}: \mathrm{F}=1: 0.5$, but slightly lower than that of commercial P25 (Figure S6). Figure 6c shows the total organic carbon (TOC) variation over BF-1 sample for the degradation of MO. Before light irradiation, the initial TOC content is $6.08 \mathrm{mg} / \mathrm{L}$; after being irradiated for 30 min the TOC content has decreased to $1.68 \mathrm{mg} / \mathrm{L}$. The result suggests that the nearly $72.4 \%$ of $\mathrm{MO}$ molecules has been completely degraded into $\mathrm{CO}_{2}$ and $\mathrm{H}_{2} \mathrm{O}$. As shown in Table 3, the BET areas of the samples follow the order of BF-0 $>$ BF-1 $>$ BF-2 $>$ BF-3 $>$ BF-4. However, their photocatalytic activities follow the order of BF-1 $>$ BF-2 $>$ BF-0 > BF-3 > BF-4. This indicates that the BET area may not the vital factor for their photocatalytic activities. According to the results of Figure 5, we assume that the improved activity of $\mathrm{BF}-1$ may mainly result from the formation of $\mathrm{BiF}_{3} / \mathrm{BiOCl}$ 
heterojunctions, which would benefit the separation and transfer rate of photogenerated charges.

Trapping Experiment. Typically, we have conducted the trapping experiments of MO dye over BF-0 (BiOCl), BF-1 (38\% BiF $/ \mathrm{BiOCl})$ and $\mathrm{BF}-4\left(\mathrm{BiF}_{3}\right)$ samples, in which ammonium oxalate and isopropyl alcohol (IPA) are used as the hole scavenger and the hydroxyl radical scavenger, respectively. In Figure 7a, the photocatalytic activity of $\mathrm{BiOCl}(\mathrm{BF}-0)$ decreases slightly, when the $20 \mathrm{~mL}$ IPA is added into the solution; while the photocatalytic activity obviously decreases when 1 mmol ammonium oxalate added. For $\mathrm{BiF}_{3}(\mathrm{BF}-4)$ sample, the IPA and ammonium oxalate have a similar effect on the photocatalytic activity, as shown in Figure 7b. As for BF-1 $\left(38 \% \mathrm{BiF}_{3} / \mathrm{BiOCl}\right)$ sample, we can see that the photocatalytic activity was obviously inhibited by ammonium oxalate, while IPA nearly does not affect the photocatalytic activity (Figure $7 \mathrm{c}$ ). The superoxide radical $\left(\cdot \mathrm{O}_{2}{ }^{-}\right)$trapping experiment is shown in Figure S7 (supporting information). The results show that the photocatalytic activity of BF-1 sample is greatly inhibited by adding $2 \mathrm{mg}$ benzoquinone (BQ), indicating superoxide radical is also the major active species. Zheng et al. have confirmed that the superoxide radical can directly degrade MO by trapping experiments and ESR results [50]. The results above indicate that the photogenerated holes is the major active oxidative specie for $\mathrm{BiOCl}(\mathrm{BF}-0)$ sample, while both hydroxyl radicals and holes are the major active oxidative species for $\mathrm{BiF}_{3}(\mathrm{BF}-4)$ sample. However, the MO degradation over $\mathrm{BF}-1\left(\mathrm{BiF}_{3} / \mathrm{BiOCl}\right.$ heterojunction $)$ was driven mainly by the superoxide radicals and holes.

Cycle Stability. In order to investigate the stability of $\mathrm{BiF}_{3} / \mathrm{BiOCl}$ heterojunction (BF-1) sample, we have further performed the cycle experiments of BF-1 sample under $\mathrm{UV}$ light irradiation $(\lambda \leq 420 \mathrm{~nm})$. After 5 cycles, the $\mathrm{BiF}_{3} / \mathrm{BiOCl}$ 
heterojunction (BF-1) nearly maintains the degradation activity of MO (Figure 8a). After 5 cycles, the XRD patterns and SEM image of BF-1 have not changed (Figure 8(b and c)), confirming a good stability of $\mathrm{BiF}_{3} / \mathrm{BiOCl}$ heterojunction.

Photosensitization. In addition, in order to avoiding dye photosensitization, we have also test the photodegradation activity of 2-nitrophenol by the samples. Figure 9(a,b) shows the degradation curves and reaction kinetic curves of 2-nitrophenol under UV light irradiation $(\lambda \leq 420 \mathrm{~nm})$. After being irradiated for $60 \mathrm{~min}$, nearly 97\% of 2-nitrophenol can be degraded by both BF-1 and BF-2 sample; in contrast, only $38 \%, 51 \%$ and $28 \%$ of 2-nitrophenol can be degraded by BF-0 (BiOCl), BF-3 and $\mathrm{BF}-4\left(\mathrm{BiF}_{3}\right)$ samples, respectively. Moreover, the degradation rates of $\mathrm{BiF}_{3} / \mathrm{BiOCl}$ (BF-1 and BF-2) sample are 5.3 and 5.8 times higher than that of phase-pure $\mathrm{BiOCl}$ (BF-0) and $\mathrm{BiF}_{3}(\mathrm{BF}-4)$, respectively. It is obvious that BF-1 and BF-2 have higher photocatalytic activities, compared with pure $\mathrm{BiOCl}$ and $\mathrm{BiF}_{3}$. The enhanced photocatalytic activity may be attributed to the formation of $\mathrm{BiF}_{3} / \mathrm{BiOCl}$ heterojunction, which benefits the separation and transfer of charges.

\subsection{A plausible photocatalytic mechanism of $\mathrm{BiF}_{3} / \mathrm{BiOCl}$ heterojunctions}

From the results above, the generation and separation efficiency of photogenerated charges plays a key role in the photocatalytic activity. Herein, we hold that $\mathrm{BiF}_{3} / \mathrm{BiOCl}$ heterojunction has significantly improved the charge separation and transfer efficiency, because their energy bands are well matched: the $\mathrm{CBs}$ of $\mathrm{BiOCl}$ and $\mathrm{BiF}_{3}$ are 0.4 and $2.02 \mathrm{eV}$, respectively; while their $\mathrm{VBs}$ are 3.91 and $6.04 \mathrm{eV}$, respectively. As illustrated in Figure 10, a stable $\mathrm{BiF}_{3} / \mathrm{BiOCl}$ heterojunction is easy to form $[45,60]$. It is well known that $\mathrm{BiOCl}$ has a unique layered structure, which is

composed of $\left[\mathrm{Bi}_{2} \mathrm{O}_{2}\right]^{2+}$ layers interleaved with $\mathrm{Cl}$ layers. Thus a strong bulk internal 
electric field can form between anion layers and cation layers, which favors for the charge separation. Besides, an interfacial electric field is easy to form between $\mathrm{BiF}_{3}$ and $\mathrm{BiOCl}$ due to their well matched energy bands. Therefore, under UV light irradiation, the photogenerated electrons at the $\mathrm{CB}$ of $\mathrm{BiOCl}$ would transfer to the $\mathrm{CB}$ of $\mathrm{BiF}_{3}$; meanwhile the generated holes at the $\mathrm{VB}$ of $\mathrm{BiF}_{3}$ would migrate to the $\mathrm{VB}$ of $\mathrm{BiOCl}$ driven by both bulk internal electric field and interfacial electric field. Herein, the recombination of electrons and holes would be obviously inhibited, and the separation efficiency would be improved.

The electrons at the surface of the $\mathrm{BiF}_{3} / \mathrm{BiOCl}$ heterojunction will react with $\mathrm{O}_{2}$ (dissolved oxygen) to form superoxide radical $\left(\cdot \mathrm{O}_{2}{ }^{-}\right)$. The trapping experiment for hydroxyl radical $(\cdot \mathrm{OH})$ indicates that $\bullet \mathrm{OH}$ has nearly no influence on the photocatalytic activity. Hence, we could speculate that the generated superoxide radicals and holes may not further react with $\mathrm{H}_{2} \mathrm{O}$ to form hydroxyl radicals $(\bullet \mathrm{OH})$ as the reactive species. Herein, we could believe that the holes and superoxide radicals will directly oxidize the MO and 2-nitrophenol (as demonstrated by the trapping experiment, Figure 7c and Figure S7), and the organic molecules are mineralized form small molecules like $\mathrm{CO}_{2}$ and $\mathrm{H}_{2} \mathrm{O}$, etc. (as demonstrated by the TOC results, Figure 6c). But, the real photocatalytic process on $\mathrm{BiF}_{3} / \mathrm{BiOCl}$ heterojunction still needs further study. 


\section{Conclusions}

In conclusion, $\mathrm{BiF}_{3} / \mathrm{BiOCl}$ heterojunction can be prepared by a simple post-synthesis method, whose optimal molar ratio of $\mathrm{BiF}_{3}$ to $\mathrm{BiOCl}$ is $38 \%$. For $\mathrm{BiOCl}$, the photogenerated electrons mainly move to the surface and accumulate on the surface; for $\mathrm{BiF}_{3} / \mathrm{BiOCl}$ heterojunction, the electrons and holes can both move to the surface and accumulate on the surface. However, nearly no electrons or holes can accumulate on the surface of $\mathrm{BiF}_{3}$. This could help us to intensively understand the charge transfer behavior from bulk to surface of semiconductor. Additionally, the trapping experiments confirm that the holes are the major oxidative species for $\mathrm{BiOCl}$ whereas both hydroxyl radicals and holes are the major active oxidative species for $\mathrm{BiF}_{3}$ sample. However, the $\mathrm{MO}$ degradation over $\mathrm{BiF}_{3} / \mathrm{BiOCl}$ heterojunction is driven mainly by the superoxide radicals and holes. The greatly improved degradation activity of $\mathrm{BiF}_{3} / \mathrm{BiOCl}$ heterojunction is mainly attributed to the improved charges separation and transfer efficiency, which has been ascribed to the synergetic effect of surface electric field, bulk internal electric field and interfaces electric field. 


\section{Acknowledgements}

This work is financially supported by National Science Foundation of China (21377060), Scientific Research Foundation for the Returned Overseas Chinese Scholars of State Education Ministry (20121707), Six Talent Climax Foundation of Jiangsu (20100292), Natural Science Foundation of Jiangsu province (BK2012464), the Key Project of Environmental Protection Program of Jiangsu (2013005), the Project Funded by the Science and Technology Infrastructure Program of Jiangsu (BM201380277), and A Project Funded by the Priority Academic Program Development of Jiangsu Higher Education Institutions (PAPD) sponsored by SRF for ROCS, SEM (2013S002). 


\section{References}

(1) A. Fujishima, Nature 238 (1972) 37-38.

(2) A. Kudo, Int. J. Hydrogen Energy 31 (2006) 197-202.

(3) H. F. Cheng, B. B. Huang, Y. Dai, Nanoscale 6 (2014) 2009-2026.

(4) P. Cui, J. Wang, Z. Wang, J. Chen, X. Xing, L. Wang, R. Yu, Nano Res. 9 (2016) $593-601$.

(5) Q. Xu, W. Lei, X. Li, X. Qi, J. Yu, G. Liu, P. Zhang, Environ. Sci. Technol. 48 (2014) 9702-9708.

(6) J. J. Branch, B. M. Bartlett, Chem. Mater. 27 (2015) 7207-7217.

(7) Y. Li, W. Xie, X. Hu, G. Shen, X. Zhou, Y. Xiang, X. Zhao, P. Fang, Langmuir 26 (2009) 591-597.

(8) Y. P. Bi, S. X. Ouyang, N. Umezawa, J. Y. Cao, J. H. Ye, J. Am. Chem. Soc. 133 (2011) 6490-6492.

(9) J. Wang, F. Teng, M. Chen, J. J. Xu, Y. Q. Song, X. L. Zhou, CrystEngComm. 15 (2013) 39-42.

(10)F. Teng, Z. L. Liu, A. Zhang, M. Li, Environ. Sci. Technol. 49 (2015) 9489-9494.

(11) Y. Shi, H. Li, L. Wang, W. Shen, H. Chen, ACS. Appl. Mater \& Inter. 4 (2012) 4800-4806.

(12) D. Wang, R. Li, J. Zhu, J. Shi, J. Han, X. Zong, C. Li, J. Phys. Chem. C 116 (2012) 5082-5089.

(13)Z. F. Huang, L. Pan, J. J. Zou, X. Zhang, L. Wang, Nanoscale 6 (2014) 14044-14063.

(14)J. Tian, Y. Sang, G. Yu, H. Jiang, X. Mu, H. Liu, Adv. Mater. 25 (2013) $5075-5080$.

(15) Y. Liu, W. Yao, D. Liu, R. Zong, M. Zhang, X. Ma, Y. Zhu, Appl. Catal B: 
Environ 163 (2015) 547-553.

(16)H. Huang, X. Li, J. Wang, F. Dong, P. K. Chu, T. Zhang, Y. Zhang, ACS Catal. 5 (2015) 4094-4103.

(17)H. Huang, J. Wang, F. Dong, Y. Guo, N. Tian, Y. Zhang, T. Zhang, Cryst. Growth Des. 15 (2015) 534-537.

(18)X. Zhang, Z. H. Ai, F. L. Jia, L. Z. Zhang, J. Phys. Chem. C 112 (2008) 747-753.

(19)J. Li, L. Cai, J. Shang, Y. Yu, L. Zhang, Adv. Mater. 28 (2016) 4059-4064.

(20)H. Li, J. Shang, Z. Ai, L. Zhang, J. Am. Chem. Soc. 137 (2015) 6393-6399.

(21)R. Qiao, M. Mao, E. Hu, Y. Zhong, J. Ning, Y. Hu, Inorg. Chem. 54 (2015) 9033-9039.

(22)C. Y. Wang, X. Zhang, X. N. Song, W. K. Wang, H. Q. Yu, ACS Appl. Mater. Interfaces 8 (2016) 5320-5326.

(23) M. Gao, D. Zhang, X. Pu, H. Li, W. Li, X. Shao, J. Dou, Sep. Purif. Technol. 162 (2016) 114-119.

(24)J. Li, Y. Yu, L. Z. Zhang, Nanoscale 6 (2014) 8473-8488.

(25)S. Yin, J. Di, M. Li, Y. Sun, J. Xia, H. Xu, H. Li, J Mater Sci. 51 (2016) $4769-4777$.

(26) W. T. Li, W. Z. Huang, H. Zhou, H. Y. Yin, Y. F. Zheng, X. C. Song, J. Alloys Compd. 638 (2015) 148-154.

(27)J. Di, J. Xia, S. Yin, H. Xu, L. Xu, Y. Xu, M. He, H. Li, RSC Adv. 4 (2014) 14281-14290.

(28)X. Zhang, L. Zhao, C. Fan, Z. Liang, P. Han, Physica B 407 (2012) 4416-4424.

(29) S. Zhang, D. Wang, L. Song, Mater. Chem. Phys. 173 (2016) 298-308.

(30) J. Di, J. Xia, M. Ji, B. Wang, S. Yin, Y. Huang, H. Li, Appl. Catal. B: Environ. 188 (2016) 376-387. 
(31)H. Li, L. Zhang, Nanoscale 6 (2014) 7805-7810.

(32)S. Bai, X. Li, Q. Kong, R. Long, C. Wang, J. Jiang, Y. Xiong, Adv. Mater. 27 (2015) 3444-3452.

(33)X. Yan, X. Zhu, R. Li, W. Chen, J. Hazard. Mater. 303 (2016) 1-9.

(34)X. Chang, S. Wang, Q. Qi, M. A. Gondal, S. G. Rashid, S. Gao, P. Wang, Dalton Trans. 44 (2015) 15888-15896.

(35)S. Weng, B. Chen, L. Xie, Z. Zheng, P. Liu, J. Mater. Chem. A. 1 (2013) 3068-3075.

(36) T. B. Li, G. Chen, C. Zhou, Z. Y. Shen, R. C. Jin, J. X. Sun, Dalton Trans. 40 (2011) 6751-6758.

(37)H. F. Cheng, B. B. Huang, X. Y. Qin, X. Y. Zhang, Y. Dai, Chem. Commun. 48 (2012) 97-99.

(38)L. Q Ye., J. Y. Liu, C. Q. Gong, L. H. Tian, T. Y. Peng, L. Zan, ACS Catal. 2 (2012) 1677-1683.

(39) B. C. Cao, P. Dong, S. Cao, Y. H. Wang, J. Am. Ceram. Soc. 96 (2013) 544-548.

(40)W. Shan, Y. Hu, Z. Bai, M. Zheng, C. Wei, Appl. Catal. B: Environ. 188 (2016) $1-12$.

(41)L. Yu, X. Zhang, G. Li, Y. Cao, S. Yu, D. Li, Appl. Catal. B: Environ. 187 (2016) $301-309$.

(42)R. Fu, X. Zeng, L. Ma, S. Gao, Q. Wang, Z. Wang, J. Lu, J. Power Sources 312 (2016) 12-22.

(43)S. Ning, L. Ding, Z. Lin, Q. Lin, H. Zhang, H. Lin, X. Wang, Appl. Catal. B: Environ. 185 (2016) 203-212.

(44)C. Feng, F. Teng, Z. Liu, C. Chang, Y. Zhao, S. Wang, Y. Zhu, J. Mol. Catal. A: Chem. 401 (2015) 35-40. 
(45)N. Li, X. Hua, K. Wang, Y. Jin, J. Xu, M. Chen, F. Teng, Dalton Trans. 43 (2014) $13742-13750$.

(46)P. Wang, T. F. Xie, H. Y. Li, L. Peng, Y. Zhang, T. S. Wu, D. J. Wang, Chem. Eur. J. 15 (2009) 4366-4372.

(47)H. Fan, T. Jiang, H. Li, D. Wang, L. Wang, J. Zhai, T. Xie, J. Phys. Chem. C 116 (2012) 2425-2430.

(48)Z. Zhang, W. Wang, L. Wang, S. Sun, ACS Appl. Mater. Interfaces 4 (2012) $593-597$.

(49)J. Xu, F. Teng, C. Xu, Y. Yang, L. Yang, Y. Kan, J. Phys. Chem. C 119 (2015) 13011-13020.

(50)X. Zheng, D. Li, X. Li, J. Chen, C. Cao, J. Fang, J. Wang, Y. He, Y. Zheng, Appl. Catal. B: Environ. 168 (2015) 408-415.

(51) Y. Ohko, K. Hashimoto, A. Fujishima, J. Phys. Chem. A 101 (1997) 8057-8062.

(52)M. Long, W. Cai, J. Cai, B. Zhou, X. Chai, Y. Wu, J. Phys. Chem. B 110 (2006) $20211-20216$.

(53) Y. Y. Zhu, Q. Ling, Y. F. Liu, H. Wang, Y. F. Zhu, Phys. Chem. Chem. Phys. 17 (2015) 933-940.

(54) Y. D. Hou, A. B. Laursen, J. S. Zhang, G. G. Zhang, Y. S. Zhu, X. C. Wang, S. Dahi, I. Chorkendorff, Angew. Chem. Int. Ed. 52 (2013)3621-3625.

(55)H. Kim, P. Borse, W. Choi, J. Lee, Angew. Chem., Int. Ed. 44 (2005) 4585-4589.

(56)N. Kavcar, Sol. Energy Mater. Sol. Cells 52 (1998) 183-195.

(57)D. P. Norton, Y. W. Heo, M. P. Ivill, K. Ip, S. J. Pearton, M. F. Chisholm, T. Steiner, Mater. Today 7 (2004) 34-40.

(58) J. Seo, P. Roushan, H. Beidenkopf, Y. S. Hor, R. J. Cava, A. T. Yazdani, Nature 466 (2010) 343-346. 
(59)L. Ye, K. Deng, F. Xu, L. Tian, T. Peng, L. Zan, Phys. Chem. Chem. Phys. 14 (2012) 82-85.

(60) Y. H. Hong, H. Y. Guai, S. Liu, R. Y. Jiang, Ceram. Int. 40 (2014) 9095-9100. 


\section{Legends of Figures}

Figure 1. X-ray diffraction (XRD) patterns (a) and scanning electron microscopy (SEM) images (b-f) of the samples: (b) BF-0 (BiOCl); (c) BF-1 $\left(\mathrm{BiF}_{3} / \mathrm{BiOCl}\right)$; (d) BF-2 (BiF $/ \mathrm{BiOCl})$; (e) BF-3 ( $\left.\mathrm{BiF}_{3} / \mathrm{BiOCl}\right)$; (f) BF-4 $\left(\mathrm{BiF}_{3}\right)$.

Figure 2. High-resolution transmission electron microscopy (HRTEM) images and selected-area electron diffraction $(\mathrm{SAED})$ patterns of $\mathrm{BF}-1\left(\mathrm{BiF}_{3} / \mathrm{BiOCl}\right)$.

Figure 3. XPS spectra of as-prepared samples: (a) Wide scan (survey); (b) Bi 4f; (c) Cl 2p; (d) F 1s.

Figure 4. (a) Ultraviolet-visible diffuse reflectance spectra (UV-DRS) of the samples;

(b) Tauc plots (Absorption ${ }^{2}$ vs. energy) of $\mathrm{BiOCl}_{\text {and }} \mathrm{BiF}_{3}$ samples.

Figure 5. (a) EIS Nyquist plots of samples; (b) Transient photocurrent densities of samples under ultraviolet light irradiation $(\lambda \leq 420 \mathrm{~nm})$; (c) PL spectra of the samples excited by 265-nm light; (d) Surface photovoltage spectra (SPV) of samples.

Figure 6. Degradation curves (a), reaction kinetic curves (b) and TOC image (c) of MO over the samples under ultraviolet light irradiation $(\lambda \leq 420 \mathrm{~nm})$.

Figure 7. Degradation curves of MO over the samples under UV light irradiation $(\lambda \leq$ $420 \mathrm{~nm})$ : (a) BF-0 (BiOCl); (b) BF-4(BiF $)$; (c) BF-1 (BiF $3 / \mathrm{BiOCl})$.

Figure 8. (a) Cycle curves of MO over BF-1 sample under UV light irradiation $(\lambda \leq$ 
$420 \mathrm{~nm}$ ); (b) XRD patterns of BF-1 before and after 5 cycles under UV light irradiation $(\lambda \leq 420 \mathrm{~nm})$; (c) SEM image of BF-1 after 5 cycles.

Figure 9. Degradation curves (a) and reaction kinetic curves (b) of 2-nitrophenol over the samples under ultraviolet light irradiation $(\lambda \leq 420 \mathrm{~nm})$.

Figure 10. Schematic diagram of photogenerated charges transfer and photocatalytic mechanism over the $\mathrm{BiF}_{3} / \mathrm{BiOCl}$ heterojunctions. 


\section{Table 1}

Atomic concentration (atom \%) and the molar ratios of $\mathrm{BiF}_{3}$ to $\mathrm{BiOCl}$ of the samples.

\begin{tabular}{|c|c|c|c|c|}
\hline Samples & $\begin{array}{c}\text { Phase } \\
\text { composition }\end{array}$ & $\mathrm{Cl} 2 \mathrm{p}$ & F 1s & ${ }^{*} \mathrm{BiF}_{3} / \mathrm{BiOCl}$ \\
\hline BF-0 & $\mathrm{BiOCl}$ & I & I & I \\
\hline BF-1 & $\mathrm{BiF}_{3} / \mathrm{BiOCl}$ & $26 \%$ & $30 \%$ & $38 \%$ \\
\hline BF-2 & $\mathrm{BiF}_{3} / \mathrm{BiOCl}$ & $24 \%$ & $47 \%$ & $65 \%$ \\
\hline BF-3 & $\mathrm{BiF}_{3} / \mathrm{BiOCl}$ & $14 \%$ & $69 \%$ & $165 \%$ \\
\hline BF-4 & $\mathrm{BiF}_{3}$ & l & I & l \\
\hline
\end{tabular}

"Notes: Calculated molar ratios from XPS results. 
Table 2

The band gap $\left(\mathrm{E}_{\mathrm{g}}\right), \mathrm{VBM}\left(\mathrm{E}_{\mathrm{VB}}\right)$ and $\mathrm{CBM}\left(\mathrm{E}_{\mathrm{CB}}\right)$ of the samples.

\begin{tabular}{ccccc}
\hline Chemicals & $\chi(e V)$ & $\mathrm{E}_{\mathrm{g}}(\mathrm{eV})$ & $\mathrm{E}_{\mathrm{VB}}(\mathrm{eV})$ & $\mathrm{E}_{\mathrm{CB}}(\mathrm{eV})$ \\
\hline $\mathrm{BiOCl}$ & 6.65 & 3.51 & 3.91 & 0.40 \\
$\mathrm{BiF}_{3}$ & 8.53 & 4.02 & 6.04 & 2.02 \\
\hline
\end{tabular}

Notes: $\chi$, the geometric mean of Mulliken's electronegativities; VBM, valence band maximum; $\mathrm{CBM}$, conduction band minimum. 
Table 3

BET areas and apparent rate constants $\left(k_{a}\right)$ of the samples for the degradation of methyl orange (MO) and 2-Nitrophenol under ultraviolet light irradiation $(\lambda \leq 420$ $\mathrm{nm})$.

Notes: BET areas, calculated by the Brunauer-Emmett-Teller (BET) method.

\begin{tabular}{cccccc}
\hline Samples & BiOCl & BF-1 & BF-2 & BF-3 & $\mathrm{BiF}_{3}$ \\
\hline BET $\left(\mathrm{m}^{2} \mathrm{~g}^{-1}\right)$ & 16.5 & 12.5 & 10.1 & 7.0 & 4.2 \\
$k_{a 1}\left(\mathrm{MO}, \mathrm{min}^{-1}\right)$ & 0.0197 & 0.0607 & 0.0479 & 0.0192 & 0.0051 \\
$k_{a 2}\left(2-\right.$ Nitrophenol, $\left.\mathrm{min}^{-1}\right)$ & 0.0097 & 0.0516 & 0.0553 & 0.0200 & 0.0088 \\
\hline
\end{tabular}




\section{Figure 1}
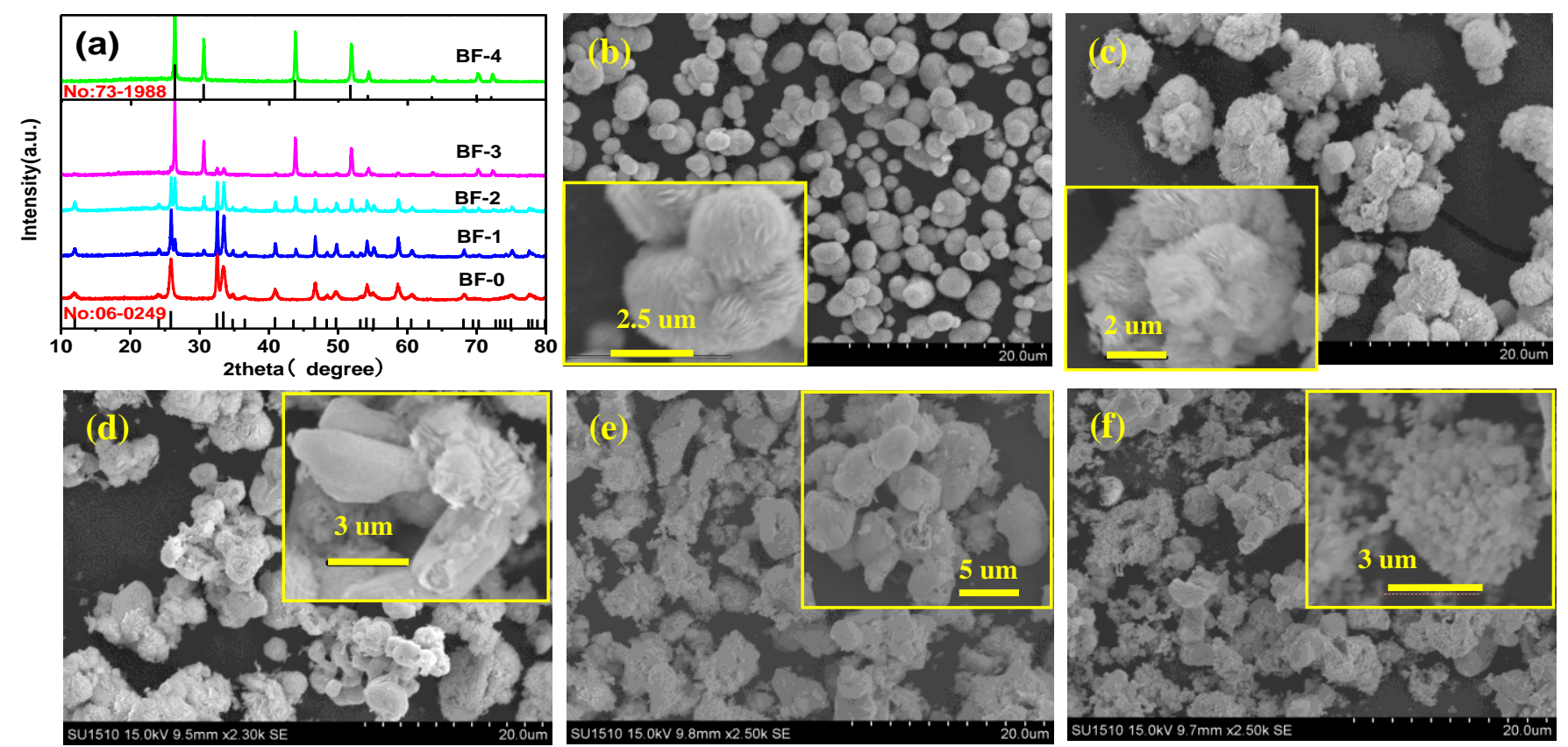

Figure 1. X-ray diffraction (XRD) patterns (a) and scanning electron microscopy (SEM) images (b-f) of the samples: (b) BF-0 (BiOCl); (c) BF-1 (BiF $/$ BiOCl); (d) BF-2 (BiF $/ \mathrm{BiOCl}) ;(\mathrm{e}) \mathrm{BF}-3\left(\mathrm{BiF}_{3} / \mathrm{BiOCl}\right) ;(\mathrm{f}) \mathrm{BF}-4\left(\mathrm{BiF}_{3}\right)$. 


\section{Figure 2}

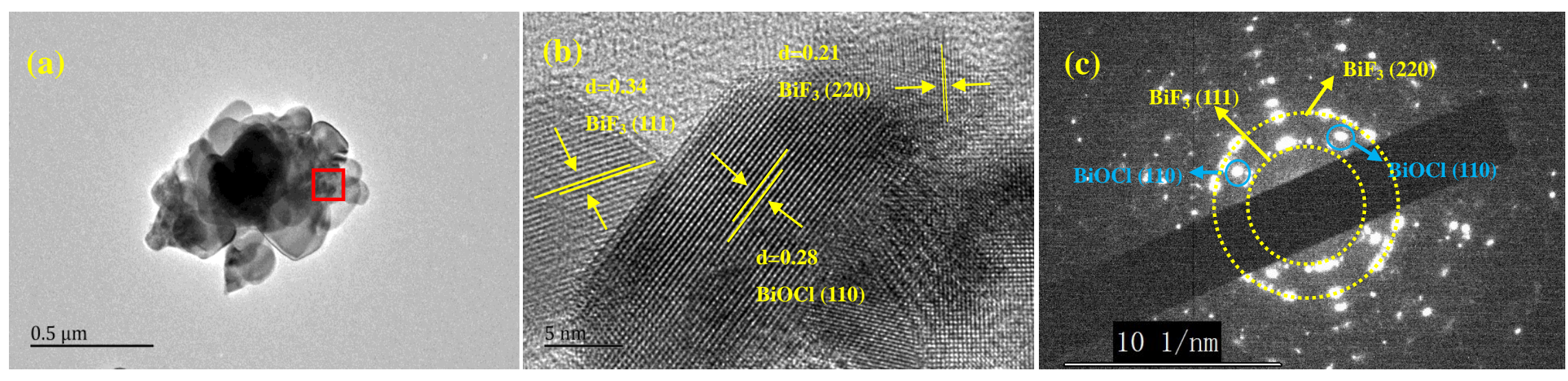

Figure 2. High-resolution transmission electron microscopy (HRTEM) images and selected-area electron diffraction (SAED) patterns of BF-1 $\left(\mathrm{BiF}_{3} / \mathrm{BiOCl}\right)$. 
Figure 3
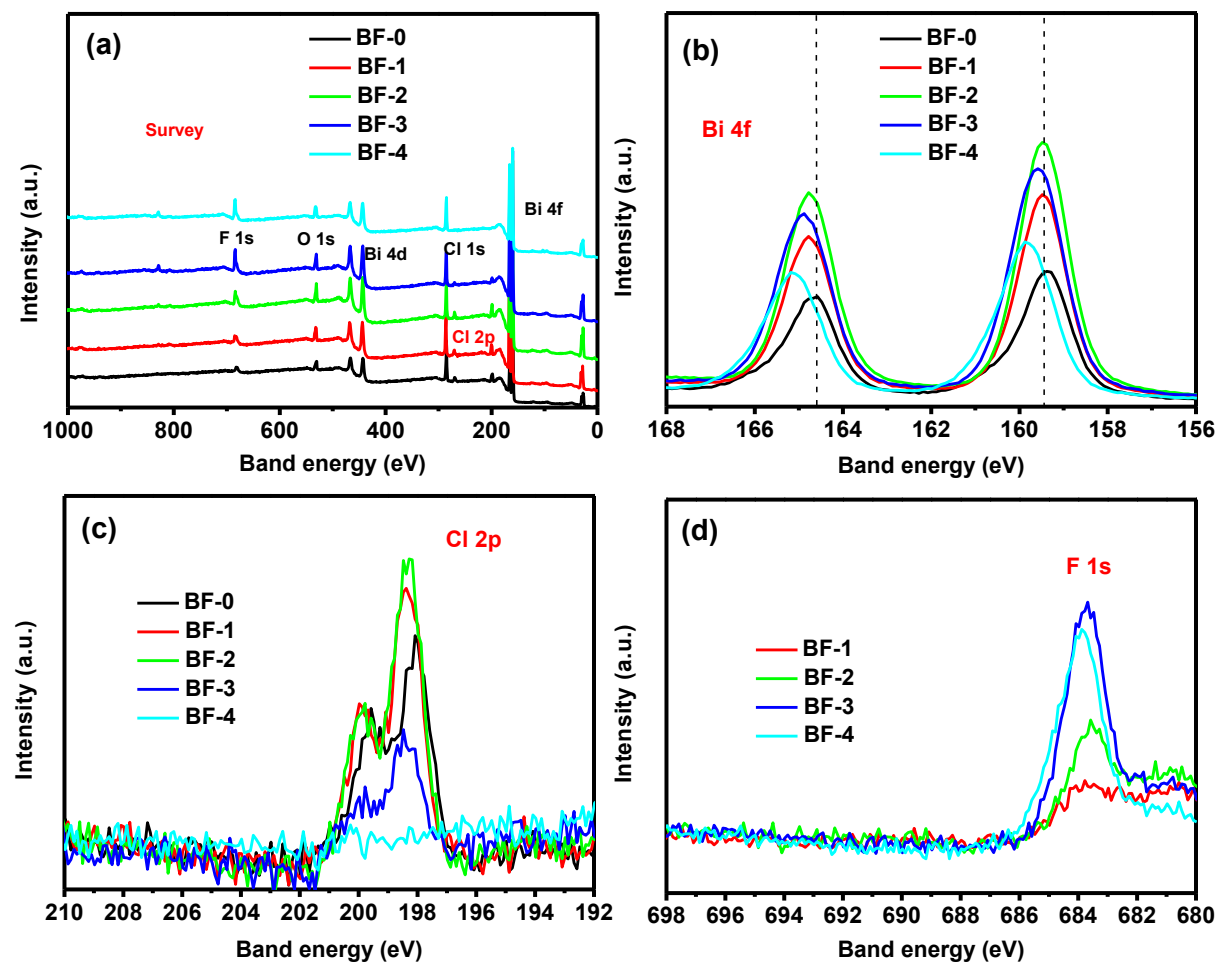

Figure 3. XPS spectra of as-prepared samples: (a) Wide scan (survey); (b) Bi 4f; (c) Cl 2p; (d) F 1s. 
Figure 4
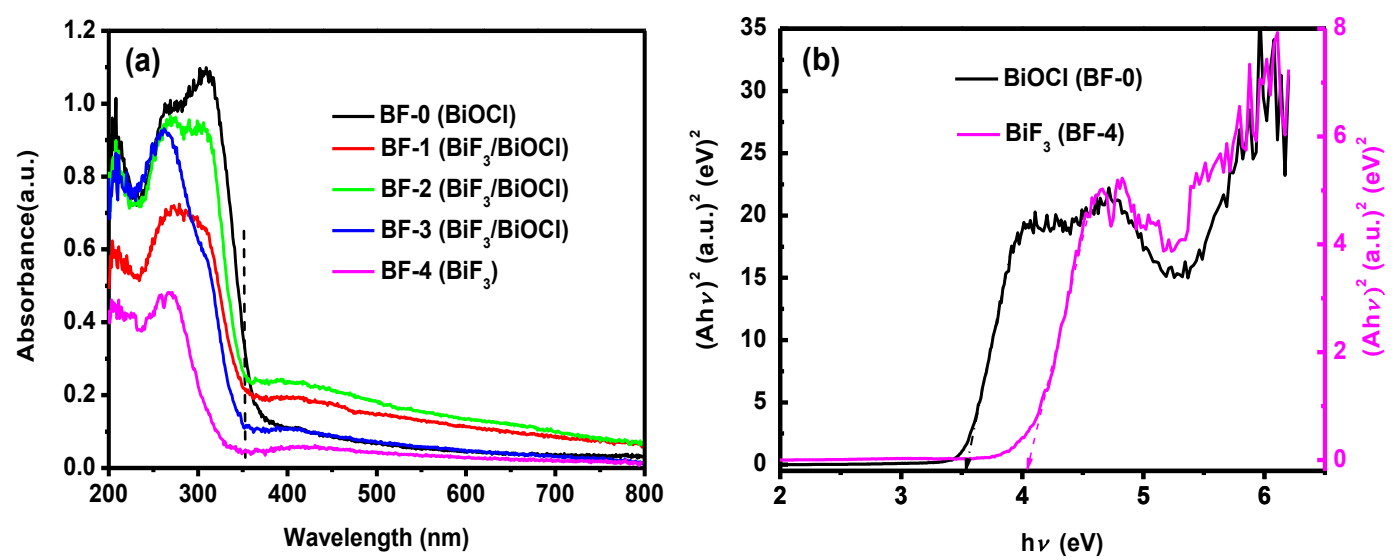

Figure 4. (a) Ultraviolet-visible diffuse reflectance spectra (UV-DRS) of the samples;

(b) Tauc plots (Absorption ${ }^{2}$ vs. energy) of $\mathrm{BiOCl}_{\text {and }} \mathrm{BiF}_{3}$ samples. 


\section{Figure 5}
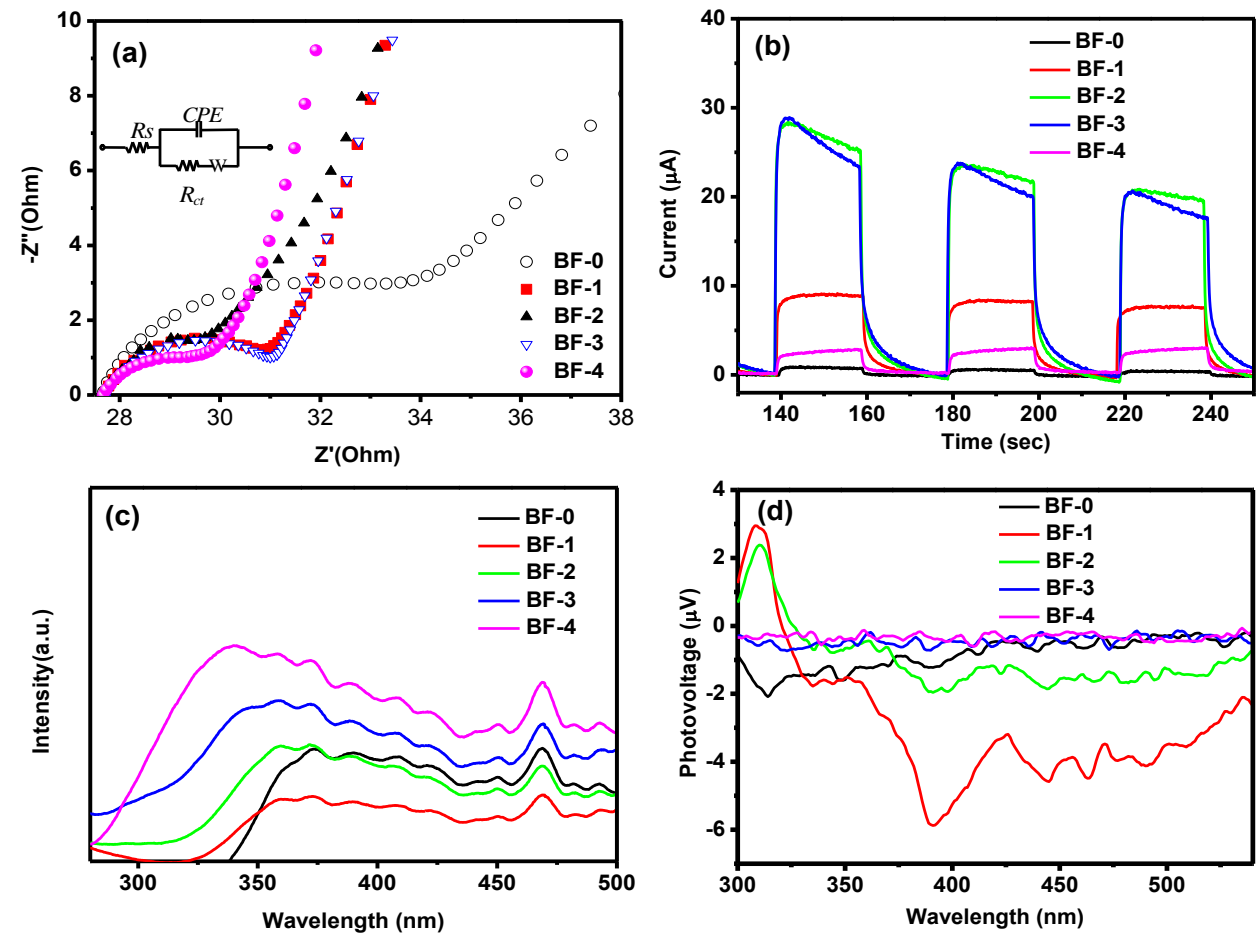

Figure 5. (a) EIS Nyquist plots of samples; (b) Transient photocurrent densities of samples under ultraviolet light irradiation $(\lambda \leq 420 \mathrm{~nm})$; (c) PL spectra of the samples excited by 265-nm light; (d) Surface photovoltage spectra (SPV) of samples. 


\section{Figure 6}
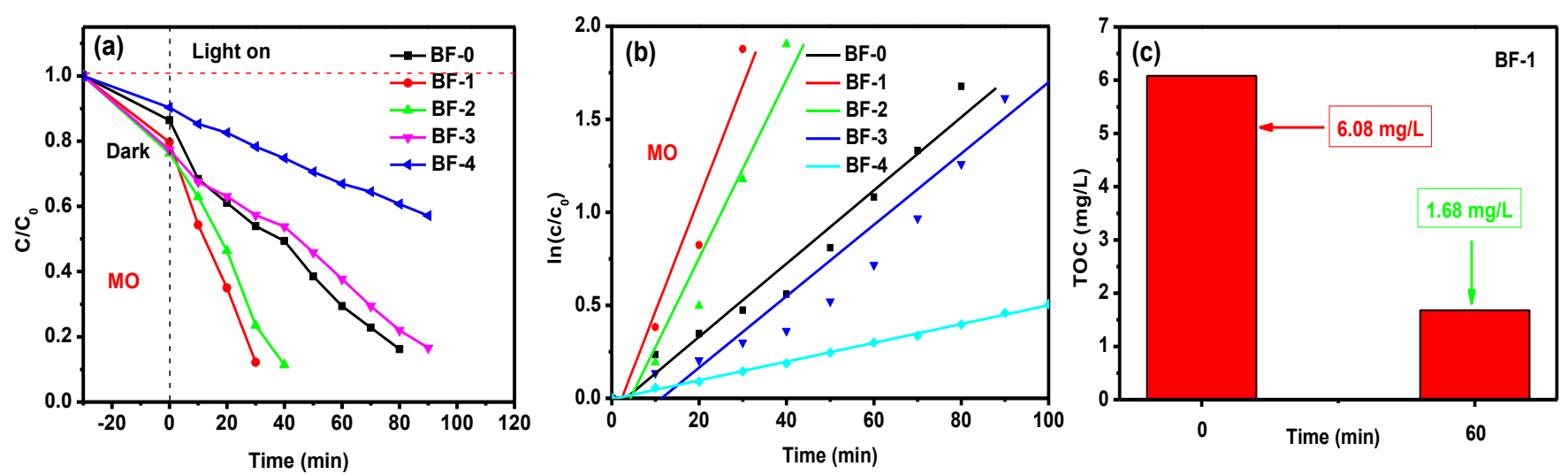

Figure 6. Degradation curves (a), reaction kinetic curves (b) and TOC image (c) of MO over the samples under ultraviolet light irradiation ( $\lambda \leq$ $420 \mathrm{~nm})$. 
Figure 7
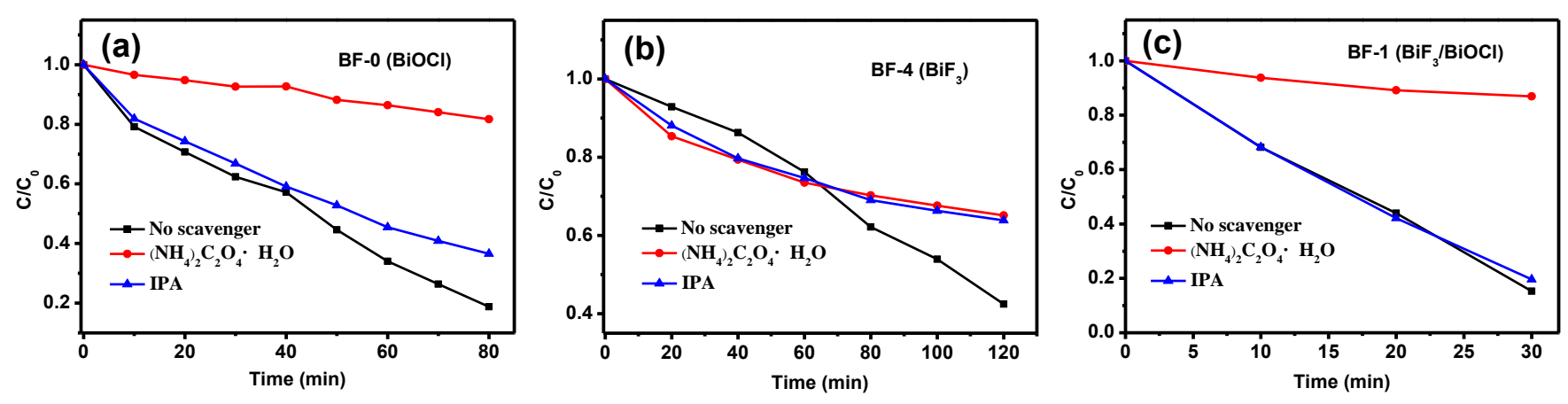

Figure 7. Degradation curves of MO over the samples under UV light irradiation $(\lambda \leq 420 \mathrm{~nm})$ : (a) $\mathrm{BF}-0$ (BiOCl); (b) $\mathrm{BF}-4(\mathrm{BiF} 3)$; (c) $\mathrm{BF}-1$ $\left(\mathrm{BiF}_{3} / \mathrm{BiOCl}\right)$. 


\section{Figure 8}
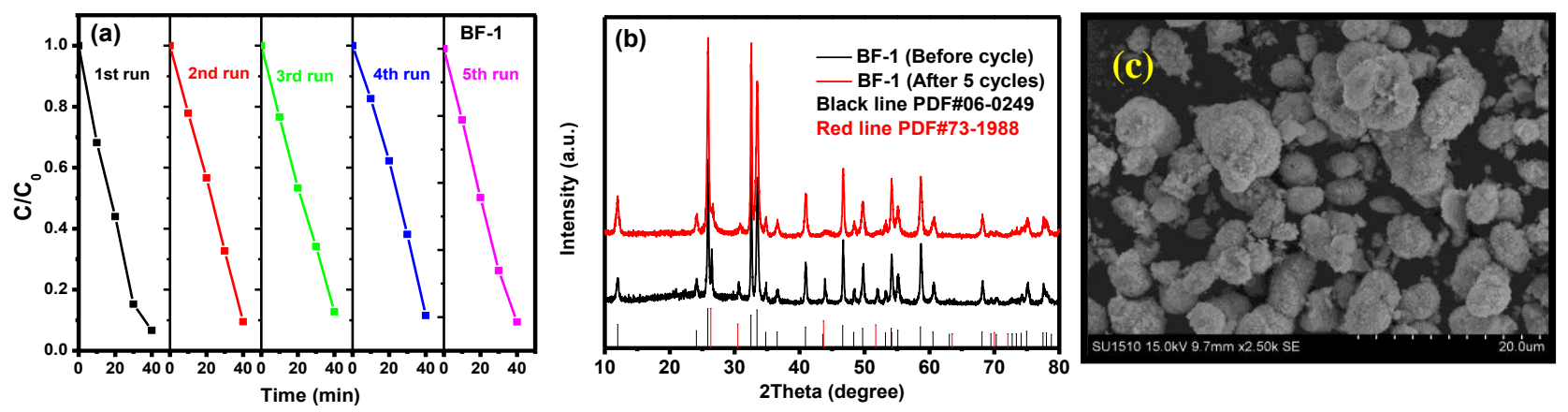

Figure 8. (a) Cycle curves of MO over BF-1 sample under UV light irradiation ( $\lambda \leq 420 \mathrm{~nm}$ ); (b) XRD patterns of BF-1 before and after 5 cycles under UV light irradiation $(\lambda \leq 420 \mathrm{~nm}$ ); (c) SEM image of BF-1 after 5 cycles. 
Figure 9
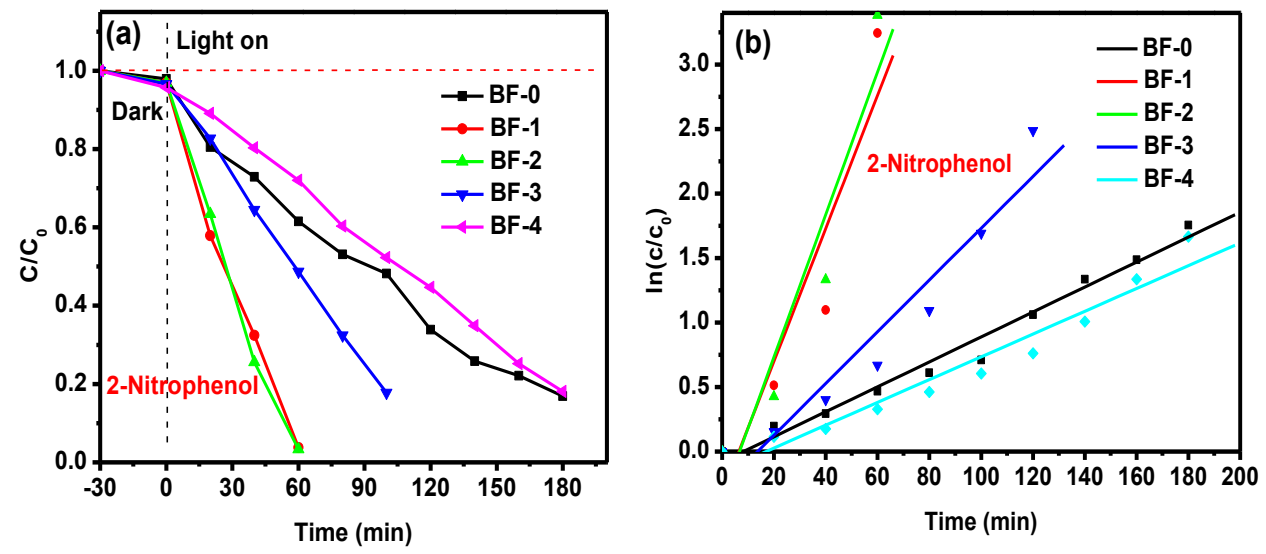

Figure 9. Degradation curves (a) and reaction kinetic curves (b) of 2-nitrophenol over the samples under ultraviolet light irradiation $(\lambda \leq 420 \mathrm{~nm})$. 
Figure 10

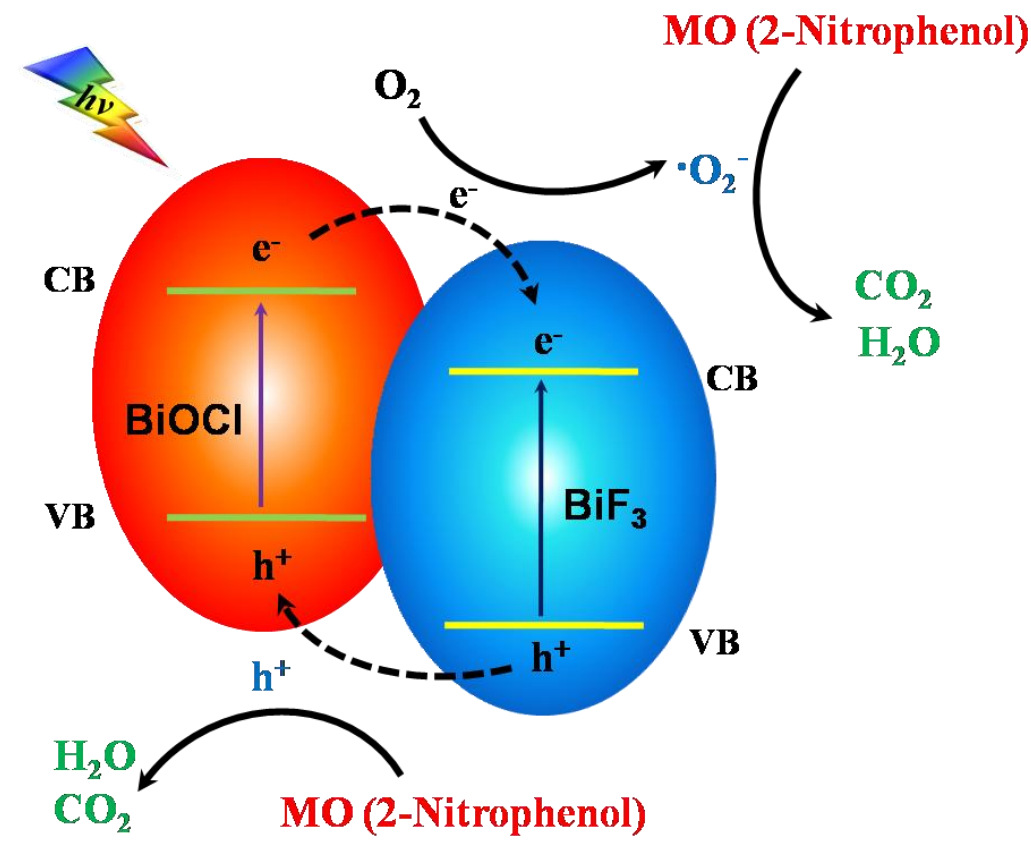

Figure 10. Schematic diagram of photogenerated charges transfer and photocatalytic mechanism over the $\mathrm{BiF}_{3} / \mathrm{BiOCl}$ heterojunctions. 


\section{Graphic abstract}

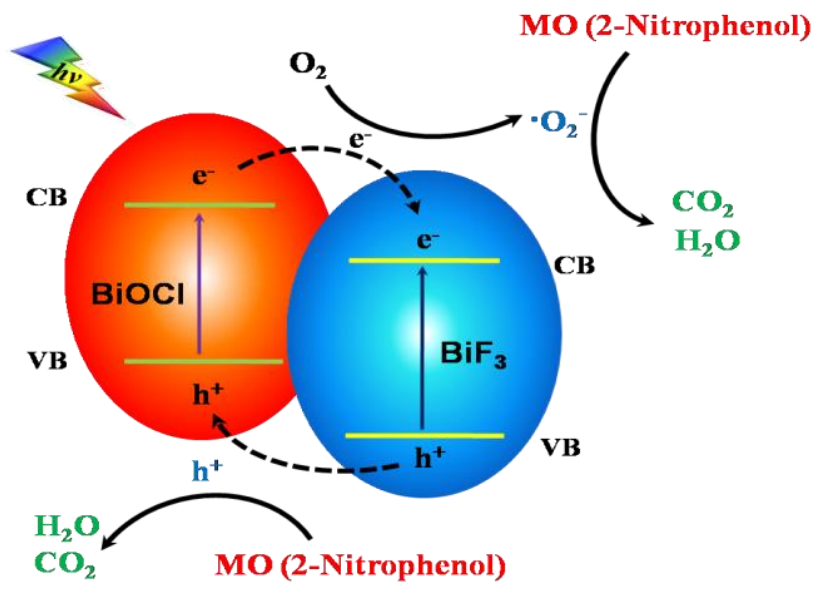

The charges transfer and separation efficiency of $\mathrm{BiF}_{3} / \mathrm{BiOCl}$ has been greatly improved by the synergetic effect of the surface electric field, bulk internal electric field and interface electric field. 